\title{
35 Research Soure \\ Reflecting on the Challenges encountered by nurses at the great Kermanshah Earthquake: A qualitative study
}

\section{Alireza Abdi}

Kermanshah University of Medical Sciences

\section{Aliakbar Vaisi -Raygani}

Kerman University of Medical Sciences

\section{Bahareh Najafi}

Kurdistan University of Medical Sciences

Hamid saidi

Urmia University of Medical Sciences

khalil moradi ( $\nabla$ moradi.khalil12@gmail.com )

Kermanshah University of Medical Sciences

Research article

Keywords: Earthquake, Nurses, Experiences, Qualitative study, Iran

Posted Date: September 22nd, 2020

DOl: https://doi.org/10.21203/rs.3.rs-38281/v4

License: (c) (1) This work is licensed under a Creative Commons Attribution 4.0 International License. Read Full License 


\section{Abstract}

Background: Iran has experienced an increasing number of earthquake disasters in the past three decades. Nurses are the largest group of healthcare providers that play an important role in responding to disasters. Therefore, this study aimed to explore the nursing challenges to provide care to the injured in the Kermanshah earthquake, Iran.

Methods: The present study was conducted as a qualitative conventional content analysis, and data collection was carried out through 16 semi-structured and in-depth interviews with the nurses involved in providing care to the injured in the Kermanshah earthquake. The data were analyzed following Graneheim and Lundman's approach.

Results: Data analysis led to the emergence of 453 primary codes, 14 subcategories, and 5 categories. The five categories were as follows: (a) organizational and managerial challenges; (b) human resources; (c) infrastructure; (d) educational system; (e) and ethical.

Conclusion: The results of this study showed that nurses faced several challenges in providing care to earthquake victims. Based on these findings, better educational management and planning, infrastructure reform, and establishment of a crisis nursing national team seem necessary.

\section{Background}

Earthquake is one of the most destructive natural disasters. Based on the international Emergency Events Database (EM-DAT), the rate of earthquakes is growing all around the world so that 792 cases have been reported between 1987 and 2015 [1]. As a developing country in Asia, Iran is one of the top 10 seismic countries in the world [2]. On the night of $12^{\text {th }}$ of November 2017 at 21:48 local time, a devastating earthquake magnitude 7.3 on the Richter scale stuck the region near the Iran-Iraq border in the West of Iran [3]. In this event, there were620 deaths, 8,000 wounded, 70,000 homeless, 4,700,000 affected by it, and $\geq 12,000$ damaged buildings [4]. After a natural disaster incidence, a surge in the demand for health and treatment services takes place [5] significance of nurses during a disaster is obvious since nurses are usually and constantly involved in disaster response by being the biggest group of human resources of health care providers in disasters, they often work in difficult conditions with restricted resources and always have more problems and challenges in their work ([6,7]. Studies have shown that the nurses who provide care services to earthquake victims encounter several challenges like resource shortages [8], personal and family safety concerns [9], health problem management [10], and moral challenges [11]. Given the high risk of earthquakes in different regions of Iran and involving the nurses in these crises, and also being unique and context-based of these challenges in previous studies $[9,12]$, it is essential to have fundamental insights about these challenges. This can be achieved using qualitative studies. The issues and challenges faced by nurses in providing care to earthquake victims have not been examined comprehensively [13]. Based on our experiences, we can achieve a basis for programming and policymaking in health care systems to face critical situations. To fill this gap in the literature, the present 
study elaborated on the challenges faced with by nurses in providing care to the victims of the Kermanshah earthquake 2017.

\section{Methods}

\subsection{Design}

A qualitative approach using conventional content analysis was performed for this study. The content analysis is an interpretation of meaning to recognize codes, sub-categories, categories, and themes [14].

\subsection{Sampling and study setting}

We purposively selected nurses with an experience of providing care to the victims of the recent Kermanshah earthquake. In our study, the interviews were continued to reach the saturation point, which was obtained by interviewing 14 nurses, but two additional interviews were performed to make certain that no new concepts were developed. To achieve the maximum variability, the participants were recruited from several teaching hospitals affiliated with Kermanshah University of Medical Science and other provinces (Tabriz, Tehran, Isfahan, Kurdistan, and Shiraz in Iran). The inclusion criteria for participants consisted of: having a direct role in providing care to the earthquake victims for at least $24 \mathrm{~h}$ in the region hit by the earthquake, having at least 1 year of work experience in clinical nursing practice, and willingness to participate in the study.

\subsection{Participants}

Mean age of the participants was $34.12 \pm 5.77$ years, with mean work experience of $10.75 \pm 5.3$ years. The majority of them were married, nine participants (56.25\%) were women and the rest were men. Eleven participants $(68.75 \%)$ had a bachelor's degree and the rest had a master's degree and had no previous experience in disaster relief work. A total of 16 participants came from emergency, Internal, Surgical, Cardiac Care Unit, and intensive care units, and all had more than 3 years of work experience. Eight participants entered the disaster site within $36 \mathrm{~h}$, they voluntarily joined rescue teams and were deployed to the most affected areas, which were Sarpol-e Zahab City and Salas-e Babajani City. The mean time period spent in the earthquake hit region was $9.18+3.65$ days (see Table 1 ).

\subsection{Data collection}

Face-to-face, semi-structured, in-depth interviews and written field notes were conducted by the corresponding author who was a PhD candidate in Nursing. Each interview took from 30 to 82 min (61 min on average) and was conducted at the nurses' workplaces in rooms where it was possible to talk privately. The interview started with questions regarding demographic data and was followed by a general question such as "What challenges did you face when providing care to the injured"? To gain clearer and in-depth information, probing questions such as "Can you give me an example of..?", "Can you explain it more?" were asked. All interviews were recorded digitally with the permission of the participants, transcribed verbatim, and imported into MAXQDA software (version10) for data 
management. Each interview was reviewed and analyzed by two authors, and the retrieved information became a guide for further data collection. Two participants refused to continue the interview due to recalling unpleasant memories while providing care earthquake.

\subsection{Data analysis}

Data collection and data analysis were performed simultaneously. To performance conventional content analysis, Graneheim and Lundman's proposed five steps were used. These stages included: (1) transcribing the interviews and reviewing them several times to reach an accurate understanding of the entire written items, (2) extracting meaning units and primary codes; (3) summarizing and categorizing the semantic units and selecting a suitable label for them, (4) modifying the primary subcategories and categories by research team; and (5) selecting an appropriate subject that has the ability to cover the categories (15). Finally, all authors discussed the analysis and agreed on the findings.

The researchers had 9 years of work experience in the emergency department. This helped them to identify implicit meanings in the participants' responses. To avert insider bias and make sure not to direct or effect the results of the study, the author used reflexivity by recording her experiences and feelings in a diary.

\subsection{Trustworthiness}

To assure study trustworthiness, we considered four criteria throughout the study process: credibility, dependability, conformability, and transferability (16).To increase credibility, the researchers performed member checks with participants during the process of data collection and analysis( text of the interview, codes and themes extracted from the interview with the participants), which were compared, matched and correct interpretations, and the concepts extracted from their experiences were confirmed. Moreover, employing the peer checking techniques, long-term and ongoing engagement with the data for supported credibility of the study. For dependability, the raw data, codes and subcategories were saved for audit purposes, and all procedures of the study and details were noted and recorded. To establish conformability, researchers shared reflective manuscripts on the research subject, permitting researchers to acknowledge prior experiences and understandings of the phenomena.In addition, researchers conscientiously performed reflective thinking to bracket individual opinions and ways of thinking. The sampling with maximum diversity was used to enhance the transferability of findings.

\section{Results}

Data analysis led to the development of 5 categories and 14 subcategories. The categories emerging from the data analysis included (1) Organizational and managerial challenges (2) human resources (3) infrastructure (4) educational system, and (5) ethical. These categories with their subcategories have been explained below (Table 2).

Table: 1 Descriptive characteristic of the participants 


\begin{tabular}{|c|c|c|c|c|}
\hline $\begin{array}{c}\text { Participant } \\
\text { No. }\end{array}$ & $\begin{array}{c}\text { Education } \\
\text { Level }\end{array}$ & Ward & $\begin{array}{c}\text { Working } \\
\text { Experience } \\
\text { (Years) }\end{array}$ & $\begin{array}{c}\text { Lengths } \\
\text { of stay(days) }\end{array}$ \\
\hline N1 & BSc & Emergency & 7 & 8 \\
\hline N2 & MSc & Internal & 16 & 5 \\
\hline N3 & BSc & Emergency & 9 & 7 \\
\hline N4 & BSc & ICU & 5 & 11 \\
\hline N5 & BSc & Surgical & 12 & 5 \\
\hline N6 & MSc & Emergency & 9 & 13 \\
\hline N7 & BSc & Surgical & 12 & 14 \\
\hline N8 & MSc & CCU & 18 & 3 \\
\hline N9 & BSc & Internal & 11 & 7 \\
\hline N10 & BSc & ICU & 16 & 14 \\
\hline N11 & BSc & Emergency & 4 & 9 \\
\hline N12 & BSc & Surgical & 13 & 10 \\
\hline N13 & BSc & offices & 22 & 15 \\
\hline N14 & MSc & ICU & 8 & 7 \\
\hline N15 & BSc & Emergency & 3 & 7 \\
\hline N16 & MSc & Emergency & 7 & 12 \\
\hline
\end{tabular}

Table 2: theme, categories, and sub-categories extracted from data

\begin{tabular}{|c|c|c|}
\hline Theme & Category & Subcategory \\
\hline \multirow{5}{*}{$\begin{array}{l}\text { Nursing care challenges in } \\
\text { earthquake }\end{array}$} & $\begin{array}{l}\text { Organizational and } \\
\text { managerial }\end{array}$ & $\begin{array}{l}\text { 1. Insufficient coordination and cooperation among } \\
\text { health team members } \\
\text { 2. Lack of unity in command } \\
\text { 3. Inadequate Organizational Management }\end{array}$ \\
\hline & Human resources & $\begin{array}{l}\text { 1.Weakness in provision of occupational health for } \\
\text { the nurses } \\
\text { 2. Poor management of volunteers } \\
\text { 3. Lack of uniforms for health workers } \\
\text { 4. Nurses' concern for their own families }\end{array}$ \\
\hline & Infrastructure & $\begin{array}{l}\text { 1.Communication disruption } \\
\text { 2. Vulnerability of local health facilities } \\
\text { Difficult access } 3 \text {. }\end{array}$ \\
\hline & Educational system & $\begin{array}{l}\text { 1. Nurses' poor knowledge in the field of disaster } \\
\text { Lack of comprehensive training program } 2 \text {. }\end{array}$ \\
\hline & Ethical & $\begin{array}{l}\text { 1. Ethical challenges related to prioritizing injured } \\
\text { 2.Ethical challenges due to lack of resources }\end{array}$ \\
\hline
\end{tabular}

\subsection{Organizational and managerial challenges}


This category represents the participants' statements about the absence of a concentrated management and programming system and poor coordination among the organizations that provided services during disasters, which lead to the following subcategories:

\subsubsection{Insufficient coordination and cooperation among health team member}

The field hospitals available in the region were not affiliated with one specific organization. They were established by different organizations and had different equipment with no coordination and arrangement among them. Because of this, the financial and human resources were not used efficiently and, in many cases, continuity of services was halted.

One participant clearly said that "The field hospitals established by the army and the University of Medical Sciences were at different places. The army hospital was fully equipped and located away from the Sar Pol Zahab mobile hospital. However, nobody knew that it was there and for a simple chest-x-ray we had to dispatch patients to Kermanshah by a helicopter" (P10).

Another participant mentioned: "There were several medical teams in some places and rural area in particular, while there were none in other places" (P5).

\section{Lack of unity in command 3.1.2.}

The nurses who experienced the Kermanshah earthquake mentioned issues and challenges like inconsistency between the requested medicines and supplied items, several command authorities, and intervention by policy makers and state authorities. This indicates a lack of unity in command, which was an issue in providing services to the victims.

For example, a participant stated that "In many cases, serums and medicines would be supplied by other provinces without supervision and need assessment so that the large supply of unrequired medicine would only limit our operation spaces" (P13).

Another participant expressed: "There were several authorities who had different strategies" (P1)

\subsubsection{Inadequate organizational management}

The nurses highlighted chaos and overlapping of operations, ambiguity of tasks, and conflicts of interest among organizations due to the obscurity of roles. This indicates negligence of the importance of organizing.

A participant stated that "The Red Crescent is not directly the medical team, but they had erected their tents inside the hospital and converted the space into a place for distributing baby formula, clothes... and it was not easy for us to tell if someone needed medical attention or not. They also intervened with nursing services and created more problem for the nursing personnel" (P13).

\section{Human resources 3.2 .}


Challenges realated human resources was another main category that was highlighted in many interviews. The participants mentioned the lack of a protocol to identify and prepare the volunteers for receiving health care. This resulted in the waste of energy and loss of quality of nursing services. Therefore, the following subcategories were emerged:

\section{Weakness in provision of occupational health for the nurses 3.2.1.}

Negligence of physical and mental health of the nurses was an issue. The majority of nurses would work nonstop; however, there were no proper welfare facilities for them. This lowered productivity of the workforces. In this regard, the participants stated:

"Because of the severity of the damages to the region, our nurses had almost lost their spirit. However, mental health of nurses was not important for anyone. The nurses were lost themselves" (P3).

"We did not have lavatory during the first 48 hours. There was no rotating work system or facilities for nurses, we had no place to sleep" (P15).

\section{Poor management of volunteers 3.2.2}

Negligence of the necessity of establishing teams and optimum use of the available forces, no list of the available skills, and inefficient distribution of relief forces lowered the efficiency of the personnel. This created a mess in terms of human forces and provision of health service during crisis. This finding was highlighted in the following statement:

"There were many nurses from different provinces who were not put in use properly. The least they could do was to let the local nurses to use vacation for a week to handle their personal affairs" (P7).

Another participant expressed: "Nursing students did not have any specific skills, they would gather around a bed trying to find a vein, but all they would do was causing more harm to the patient" (P2).

\section{Lack of uniforms for health workers 3.2.3.}

Failure to distinguish available forces based on their skills and establish specialized teams (many did not have an ID card or a proper uniform) created space for the opportunistic so that it was not easy for careseekers and authorities to find a professional care giver.

One of the nurses said: "Many nurses and physicians in the region did not have an ID card or a uniform. There was this guy who claimed to be a pediatrician and took medicines to villages nearby. Later we found that he was a welder" (P4).

\section{Nurses' concern for their own families 3.2.4.}


The first concern for the local nurses was their families and their safety. This was a mental engagement for them that prevented them from providing quality care to the injured. In this regard, the participants stated:

"First, you need to make sure about your own family; otherwise, the concern affects your work. How can I stay at work when I am not sure if my family is alive or not" (P4).

Another participant mentioned: "My baby and husband were in the car outside the hospital. Every few hours I would return to them to breastfed my baby and then return to work. I was highly under pressure" (p8).

\section{Infrastructure 3.3.}

Another category extracted from the participants' experiences was "challenges caused by infrastructure." The findings showed that the participants encountered several challenges in this regard.

\section{Communication disruption 3.3.1.}

Immediately after earthquake, the telecommunication services in the region were halted so that communication for making arrangements to manage the crisis was a serious challenge for the personnel. A participant said that "The telephone service was off and mobiles were not working. It was very hard to contact the province crisis control center and other relief centers" (P1).

\section{Vulnerability of local health facilities 3.3.2}

Chaos in primary medial aids, due to serious damages to the health infrastructure, power outage, and darkness had a negative effect on the quality of services provided by the nurses. One of the participants noted: "After the earthquake, almost all health care centers were out of commission. The staff would provide health service at the hospital yard (very cold weather) using their mobile light" (P14).

\section{Difficult access 3.3.3.}

Heavy road traffic due to the stampede and massive destruction on the streets near the hospital in particular was one of the main causes of disorder in providing health care by nurses. In this regard, one of them stated that"It was a real mess. There were many injured on the way to the hospital who were stuck in the traffic $1 \mathrm{~km}$ away from the hospital. We would have been more helpful if we had access to the injured" (P12).

\section{Educational system 3.4.}

Challenges of the education system was another main category found in the study. Interviews showed that nurses were not prepared to face disasters and had not received adequate education in this area, 
which lead to the following subcategories:

\subsubsection{Nurses' poor knowledge in the field of disaster}

Many of the participants acknowledged their lack of knowledge and skill for providing care to earthquake victims. They highlight this as a critical care void in their profession and emphasized on the necessity of education. In this regard, the participants stated:

"The nurses were not familiar with the protocols of carrying patient, safety, and flight physiology. They did not know how to carry patients by helicopter" (P8).

Another participant expressed: "Many of the injured had suffered crush syndrome; however, most of the nurses knew nothing about it" (P9).

\subsubsection{Lack of comprehensive training program}

The nurses mentioned their lack of readiness and they believed that it was due to a gap in the formal education system and in-service educations.

One participant highlighted this: "We had no education about crisis; all we had was a two-credit course in the bachelors' program" (P11).

Another nurse expressed: "Due to the lack of integrity and harmony in educational programs on crises, our nurses were not able to demonstrate their true capabilities during the crisis" (P6).

\subsection{Ethical}

Almost all the participants mentioned moral challenges they faced when providing health cares to the earthquake victims. They had also found these challenges disturbing optimal care. For this reason, their statements revealed following subcategories.

\subsubsection{Ethical challenges related to prioritizing injured}

As revealed by the interviews, when the disaster is large in scale, the nurses face hard decision-making situations. In many cases, they have to make unfair and unpleasant decisions and in some cases these decisions are about life or death. In this regard, the participants stated:

"It was a very frustrating situation, it was not easy to decide which one should be attended first, that child, that adult or that elderly...." (P5).

One of the participants noted: "One of the victims had an apnea and we needed resuscitation trolly, aftershocks would not stop and the building was collapsing. It was not able to decide whether or not should I risk my life and go inside the building to fetch the trolley" (P11). 


\subsubsection{Ethical challenges due to lack of resources}

During disasters, material and human resources scarcity is common. As a result, staff being unable to provide all services in the event of a disaster, this creates specific moral dilemmas for the nurses. The nurses talked about their experiences as conflicts between their knowledge of standard performance and failure to meet the standard. This was a source of moral challenge for them.

One of the nurses stated: "We had to use one forceps for several patients with cuts; I do not if our job was ethical or not...." (p14).

\section{Discussion}

In this study, the nurses' experience regarding the challenges faced of providing care to earthquake victims was examined. Semi-structured interviews were performed and the data analysis yielded five categories. Organizational and managerial challenge was one of the main extracted categories. According to the participants, different organizations like the ministry of health, the Red Crescent, and other relief organizations were in charge or providing services to care-seekers. These organizations worked independently and there was no coordination among them.

Pouraghaei et al. studied Azerbaijan earthquake in 2012 and highlighted the lack of coordination among organizations as one of the main challenges [17]. Another study by Li et al. on Sichuan earthquake in China, they pointed to the lack of collaboration among disaster relief teams and insufficient leadership. [18].Apparently, one of the challenges of modern age, given the type of disasters, is the necessity of an integrated system to face disasters.

Human resources challenge was another extracted category in this study. The participants highlighted issues like lack of welfare facilities for care givers like accommodation facilities, nutrition, bathrooms, and negligence of mental health of nurses. Other studies have reported similar concerns in nurses like personal safety, adequate food, water, and accommodations $[19,20]$. Hugelius et al. noted that providing psychological support was one of the main elements in nursing services in the face of disasters [21]. In addition, Salmani et al. noted that volunteers' potential problems and their physical and mental status should be assessed during and after disasters. [22]. The participant mentioned ineffective call and distribution of relief forces in the regions hit by the earthquake, lack of uniform, and their concerns about safety of their families. Studies on Sichuan earthquake in China and the Bam earthquake have highlighted poor human resource organization as well $[18,19]$. Despite the fact that health and treatment personnel were present in the region, they were not known to officials and clients in the early days. In the case of the Bam and Azerbaijan earthquakes, some of the volunteers did not have uniform and ID card $[17,19]$. Providing dress to distinguish the health providers and the ranking is fundamental to handle the disaster.

Despite the valuable role of nurses in the earthquake region, they and their families received no mental, financial, and emotional support. Similar problems have been reported in other studies $[9,17,23]$. Nursing 
Organization can take steps in this regard by providing protection and support for nurses and their families during disasters as incentives for nurses. Such services solve the concerns in nurses and improve their capability to provide health services.

Another main category was infrastructural challenges. The participants had experienced several challenges in this field. Ardalan et al. reported that due to communicational problems and the demolition of three health centers and 89 local clinics failed to play an efficient role during the first phase of reaction to Azerbaijan earthquake [24]. Infrastructure disruption after disasters have been mentioned in several study as a serious challenge $[25,26]$.

Another extracted challenge was about education system. Many of the participants acknowledged the lack of skills and knowledge for providing health care in disaster and absence of a comprehensive education program in this regard. A systematic review in 2017 showed that nurses were not ready to work in disasters; most of the reviewed studies were from Asian countries [27]. Like many other countries, crisis nursing education is not completely developed in Iran and nurses do not have the knowledge and skill to work in disasters due to lack of education [13]. Empowerment of nurses and improvement of their awareness can be a major step to provide timely and proper services to victims during disasters. Theoretical and practical educations should be a part of nursing program to improve performance of nurses during disaster.

Another category based on the experiences of nurses was moral challenges. Some of the participants mentioned situations full of moral challenges and that they had no education in this regard. Moral challenges in providing care to the victims while the safety of nurse is at risk were discussed. These findings are consistent with other studies on nurses who helped earthquake victims and faced with moral challenges $[9,11,28]$. Studies have shown that serious lack of resources and hard situations create moral challenges like whether or not washing equipment with drinking water is a right thing to do. Similarly, nurses in our study also reported such practices as using one forceps for multiple injuries $[8,29]$. Moral preparedness of nurses who are the front line of providing care services during disaster neglected and they suffer the consequences of different professional and moral challenges afterwards [9].

\section{Limitations}

There are several limitations that should be considered when interpreting the findings of study. The study findings are a reflection of the experiences of a small group of nurses attending an earthquake zone in one province of Iran. Therefore, the findings must be generalized with caution. To alleviate this limitation, the participants were selected from different provinces with maximum diversity. Despite providing rich information of the concept under study, the time gap between the actual experiences and the interviews could also cause concerns about accuracy of the recollections.

\section{Conclusion}


The nurses faced with several challenges in providing care to earthquake victims. Five main categories were extracted and most important of them was human resources and education system challenge that need serious, efficient, and effective intervention to ensure better care services in similar situations in the future. Similar challenges had been experienced in previous earthquakes like the Roudbar, Bam, and Azerbaijan earthquakes. Experiencing the same challenges in Kermanshah earthquake indicates negligence in the authorities to solve these challenges. Given the crisis nursing status in Iran, better curriculum planning and implementation, revision of nursing curriculum, and establishing crisis nursing national team (professional pre-identified volunteers) are essential measures to improve professional competence of nurses in the face of disasters.

\section{Abbreviations}

BSc: Bachelor of Science; MSc: Master of Science; ICU: intensive care unit; CCU: cardiac care unit.

\section{Declarations}

\section{Ethics approval and consent to participate}

The study was approved by the Research Council and Ethics Committee of Urmia University of Medical Science (IR.UMSU.REC.1398.042). Before the interview, written and verbal information about the study were given and written informed consent was attained from all participants. Their participation was voluntary and they had the right to withdraw from the study at any stage.

\section{Consent for publication}

The article does not contain any individual's details and consent forpublication is not applicable.

\section{Availability of data and materials}

Data are available by contacting the corresponding author.

\section{Competing interests}

All authors declare that they have no competing interests.

\section{Funding}

This research is part of $\mathrm{PhD}$ thesis and did not receive any grant fromfunding agencies in the commercial or not-for-profit sectors. This project was supported by the research deputy of Urmia University of Medical Sciences. The funding body had no role in the design of the study, data collection, analysis, inter-pretation of data, or writing the manuscript.

\section{Authors' contributions}


All authors participated and approved the study design. AA, and KM contributed to design the study, KM collected the data, and analyzed by AA, AVR, BN and HS. The final report and article were written by AA, $\mathrm{KM}$ and AVR and all authors read and approved the final manuscript.

\section{Acknowledgements}

The authors give their special thanks to all authorities and nurses that supported them in all stages of the study

\section{References}

1. 1.Guha-Sapir D, Below R, Hoyois P. EM-DAT: International Disaster Database (Brussels-Belgium: Université Catholique de Louvain). https://www.emdat.be. Accessed 14 August 2019.

2. Moosazadeh M, Zolala F, Sheikhzadeh K, Safiri S, Amiresmaili M. Response to the Bam earthquake: a qualitative study on the experiences of the top and middle level health managers in Kerman, Iran. Prehosp Disaster Med. 2014;29(4):388-91.

3. Nobakht HN, Ojagh FS, Dale KY. Risk factors of post-traumatic stress among survivors of the 2017 Iran earthquake: The importance of peritraumatic dissociation. Psychiatry Res. 2019;271:702-7.

4. Moradi K, Abdi A, Valiee S, Rezaei SA. Nurses' experience of providing ethical care following an earthquake: A phenomenological study. Nurs Ethics 2020; 27(4):911-23.

doi:10.1177/0969733020907952

5. Cianelli R, Wilkinson C, Mitchell E, Anglade D, Nicolas G, Mitrani V, et al. Mental health training experiences among H aitian healthcare workers post-earthquake 2010 Int Nurs Rev. 2013;60(4):52835 .

6. Phakdeechanuan K, Songwwathana P, Sae-Sia W. Thai nurses' learning needs regarding disaster nursing: High needs. Nurs Med J of Nursing. 2015;5(2):56-66.

7. Jennings-Sanders A, Frisch N, Wing S. Nursing students' perceptions about disaster nursing. Disaster Management \& Response. 2005 Jul 1;3(3):80-5.

8. Sloand $\mathrm{E}, \mathrm{HoG}, \mathrm{Kub}$.Experiences of nurse volunteers in Haiti after the 2010 earthquake.ResTheory Nurs Pract,2013; 27(3):193-213.

9. Pourvakhshoori N, Norouzi K, Ahmadi F, Hosseini M, Khankeh H. Nurse in limbo: A qualitative study of nursing in disasters in Iranian context. PloS one. 2017;12(7).

10. Shih FJ, Liao YC, Chan SM, Duh BR, Gau ML. The impact of the 9-21 earthquake experiences of Taiwanese nurses as rescuers. Soc Sci Med. 2002 Aug 1;55(4):659-72.

11. Wenji Z, Turale S, Stone TE, Petrini MA. Chinese nurses' relief experiences following two earthquakes: implications for disaster education and policy development. Nurse Educ Pract. 2015 Jan 1;15(1):7581.

12. MIURA S, KONDO A, TAKAMURA Y. Practices and challenges of disaster nursing for Japanese nurses sent to Nepal following the 2015 earthquake. Health Emergency and Disaster Nursing. 2020 Apr 
15;7(1):46-54.

13. Zarea K, Beiranvand S, Sheini-Jaberi P, Nikbakht-Nasrabadi A. Disaster nursing in Iran: Challenges and opportunities. Australas Emerg Nurs J. 2014 Nov 1;17(4):190-6.

14. Hsieh HF, Shannon S. Three approaches to qualitative content analysis, Qual Health Res 2005; 15(9):1277-88

15. 15. Graneheim UH, Lindgren BM, Lundman B. Methodological challenges in qualitative content analysis: a discussion paper. Nurse Educ Today 2017;56:29-34.

16. Lincoln YS and Guba EG. But is it rigorous? Trustworthiness and authenticity in naturalistic evaluation. New Dir Program Eval 1986; 1986: 73-84.

17. Pouraghaei M, Jannati A, Moharamzadeh P, Ghaffarzad A, Far MH, Babaie J. Challenges of hospital response to the twin earthquakes of august 21, 2012, in East Azerbaijan, Iran. Disaster Med Public Health. 2017 Aug;11(4):422-30.

18. Li YH, Li SJ, Chen SH, Xie XP, Song YQ, Jin ZH, Zheng XY. Disaster nursing experiences of Chinese nurses responding to the Sichuan Ya'an earthquake. Int Nurs Rev. 2017 Jun;64(2):309-17.

19. Saghafinia M, Araghizade H, Nafissi N, Asadollahi R. Treatment management in disaster: A review of the Bam earthquake experience. Prehosp Disaster Med. 2007 Dec;22(6):517-21.

20. O'Boyle C, Robertson C, Secor-Turner M. Nurses' beliefs about public health emergencies: fear of abandonment. Am J Infect Control. 2006 Aug 1;34(6):351-7.

21. Hugelius $\mathrm{K}$, Adolfsson A. The HOPE model for disaster nursing-A systematic literature review. Int Emerg Nurs 2019 Apr 17.

22. Salmani I, Seyedin H, Ardalan A, Farajkhoda T. Conceptual model of managing health care volunteers in disasters: a mixed method study. BMC Health Serv Res. 2019 Dec;19(1):241.

23. Geisz-Everson MA, Dodd-McCue D, Bennett M. Shared experiences of CRNAs who were on duty in New Orleans during Hurricane Katrina. AANA J 2012; 80(3):205.12.

24. Ardalan A, Babaie J, Moradian MJ, Shariati M, Yousefi $\mathrm{H}$. Incorporating the lessons learned from the 2012 East Azerbaijan earthquakes in Iran's national health emergency plan. Prehosp Disaster Med. 2013 Aug;28(4):417.

25. Chang SE, McDaniels T, Fox J, Dhariwal R, Longstaff H. Toward disaster-resilient cities: Characterizing resilience of infrastructure systems with expert judgments. Risk Ana. 2014 Mar;34(3):416-34.

26. Sorani, M, Tourani, S, Khankeh, HR, et al. Prehospital emergency medical services challenges in disaster: a qualitative study. Emerg (Tehran). 2018, 6(1):e26. Google Scholar | PubMed

27. Labrague LJ, Hammad K, Gloe DS, McEnroe-Petitte DM, Fronda DC, Obeidat AA, Leocadio MC, Cayaban AR, Mirafuentes EC. Disaster preparedness among nurses: a systematic review of literature. Int Nurs Rev. 2018 Mar;65(1):41-53.

28. Li Y, Turale S, Stone TE, Petrini M. A grounded theory study of 'turning into a strong nurse': earthquake experiences and perspectives on disaster nursing education. Nurse Educ Today. 2015 
Sep 1;35(9):e43-9.

29. Yang YN, Xiao LD, Cheng HY, Zhu JC, Arbon P. Chinese nurses' experience in the Wenchuan earthquake relief. Int Nurs Rev. 2010 Jun;57(2):217-23.

\section{Supplementary Files}

This is a list of supplementary files associated with this preprint. Click to download.

- Cheklist.docx 